\title{
Implicit/Explicit Speech and Relationships between Girls/Boys Students in Team Sport Learning (Case of Tunisian Basketball)
}

\author{
Rim Mekni, Hajer Sahli, Chamseddine Guinoubi, Wissam Ben Khalifa, Makrem Zghibi \\ Research Unit, "Sportive Performance and Physical Rehabilitation", High Institute of Sports and Physical \\ Education, Kef, University of Jendouba, Jendouba, Tunisia \\ Email: makwiss@yahoo.fr
}

Received 12 June 2015; accepted 22 April 2016; published 25 April 2016

Copyright (C) 2016 by authors and Scientific Research Publishing Inc.

This work is licensed under the Creative Commons Attribution International License (CC BY). http://creativecommons.org/licenses/by/4.0/

c) (i) Open Access

\section{Abstract}

The intervention of the context, which represents the situation where the speech is delivered, upsets the logic so that the semiotic meaning produced by the situation of enunciation takes precedence over that of departure. This difference in meaning between "what is said" and "what is covered" was taken by the "pragmatic discourse" which focuses on the elements of language in context and in co-text. Austin (1970) distinguishes three speech acts: the elocutionary act, the illocutionary act and perlocutionary act that will be studied in the context of school and classroom of EPS basketball. An analysis of various acts of implicit and explicit language will allow studying the reports of site (Kerbrat-Orecchioni, 2001) between girls and boys. All statements are of assertive type referred to with the order constituting instructions to remedy the failure. Most are accompanied by a brief argument that explains the cause or the consequence of the performed act. Although girls seem to take part in the discussion, their actions remain less important. If language is a form of action, if any statement is already pragmatically loaded, this charge is its propensity to act on others and to produce effects.

\section{Keywords}

Speeches, Implicit, Explicit, Balance of Power and Basketball

\section{Introduction}

The nature of action strategies adopted by a subject in team sport learning shows that some information is privileged over others. This context depends on the meaning that the subject gives to the task and not only depends

How to cite this paper: Mekni, R., Sahli, H., Guinoubi, C., Khalifa, W. B., \& Zghibi, M. (2016). Implicit/Explicit Speech and Relationships between Girls/Boys Students in Team Sport Learning (Case of Tunisian Basketball). Creative Education, 7, 687696. http://dx.doi.org/10.4236/ce.2016.74072 
on external requirements but also to his own perception of these conditions.

Any statement carries a definite meaning, obtained by the combination of different word's semantics that constitute it. The words are organized according to a strict well-determined group of syntax rules. What about context?

The intervention of the context, situation in which the speech is delivered, disrupts the logic of things so that the meaning produced by the situation of enunciation takes precedence over that of departure. This difference in meaning between what is said and what is referred was taken over by the "pragmatic" as an object of study. As a result, the discipline of linguistics focuses on language elements whose meaning can be understood by grasping the context. To better structure the study, Austin (1970) distinguishes at the eighth conference, that when saying is doing, three speeches act, which are:

$\checkmark$ The elocutionary act: the act of saying something. It is the combination of different speech sounds, mentioned and linked by syntax rules. In other words, the act provides a statement.

$\checkmark$ The illocutionary act: the act performed by saying something. The sentence production is an act in itself and it transforms the relationship between the stakeholders. Thus, any forward product engages the listener. Such acts can be distinguished: act of promising, questioning, informing, act to order, act to insinuate, act of offending, etc. Finally, note that this act is a conventional act, which implies a social agreement.

$\checkmark$ The perlocutionary act: Instead of stating a simple act, each statement refers to a well-determined one. Thus, interviewing someone can be designed to accommodate him, to embarrass him, to make him believe that we agree with his views, etc... Unlike the illocutionary act, this is an act that can remain hidden: to embarrass someone, there is no need to let him know we are trying to do so (Zghibi, 2009).

To get a clear idea of these three acts, the following examples set by Katherin Kerbrat-Orcchioni (2008), will make it clear:

1) John smokes a lot.

2) Does John smoke a lot?

3) Smoke a lot, John!

Prepositional phrases with the same content perform the same illocutionary act as ascribes to the same subject the same attribution, the "smoke a lot". However, they do not convey the same illocutionary, which are respectively: assertion, question and order. Likewise their pure perlocutionary act, insofar as the first statement aims to inform, the second request information, while the latter is rather a reproach (Zghibi, 2009).

\section{Methodology}

The didactic situation is to arrange a time to discursive interaction as a "debate of ideas" (Gréhaigne \& Godbout, 1998; Gréhaigne, 2009) between the students $(5 \times 5,3$ teams, boys team, girls team and a third mixed team girls and boys aged 17 years), with/without the teacher $\left(T=3 \times 8^{\prime}\right)$ before/after a game $\left(3 \times 8^{\prime}\right)$ basketball court (Zghibi et al., 2010).

Longitudinal observation of the changing balance of power game and the verbal exchanges between students took place over a cycle of 8 learning sessions. The aim of this corpus is to present the pragmatic value of speeches produced by the protagonists of the game. This is to describe the evolution of verbal exchanges in relation to the balance of power in the game. In parallel with these changes simultaneously reflexive postures of students who make rules and explore effective action by returning to the game.

Each session consists, then, three game situations $(\mathrm{T}=8)$, under the control of the teacher, interspersed by two sequences of verbalization $(t=3)$, in the presence of a teacher and another in his absence, consisting of narrating the facts and argue about a collective strategy. The teacher launches open questions like: what has happened? How to explain what happened? and how to move forward together?

The analysis of verbal production students will be in using a model developed in conversational analysis (Kerbrat-Orecchioni, 1998) and to identify the implicit and explicit discursive context.

So we opt for a purely descriptive analysis that aims to convey the language typologies of students through analysis models from the language of science (Roulet, 1981; Kerbrat-Orecchioni, 1998).

Participants in this study were the third secondary grade students (average age $=17$ years) secondary school Bizerte Northern Region in Tunisia.

Gréhaigne traces four major periods in the development of cognitive structures, which at this age, students are able to problematize it, referring to the proposed situations, assumptions about the problems encountered and the 
means to develop its projects. This is the stage of understanding to succeed and to succeed is to understand the problematization by student before/after action.

\section{Analysis of Different Speech Acts}

\subsection{Implicit and Explicit Pupils' Speeches}

This pragmatic dimension of language is simply a sign of its wealth. Far from being specific to any language, we will adopt this approach to study the implicit and explicit mention of Tunisia in our corpus. The study will subsequently form a clear idea about the relationship between pupils:

- Meeting 1

"Not only have we missed a number of shots on goal but we full of faults." (Act locutionary)

-Illocutionary act: inform.

-Perlocutionary act: criticism

Being assertive at the base, this statement tells us about the game's outcome, which is disappointing because the team missed the game. Aimed primarily at the player's colleagues, the statement loses its value since the recipient officially knows the illocutionary content. Thus he spoke as reproach: the speaker reformulates dissatisfaction with the outcome, which would be shameful. Besides the connectors against argumentative "not only ... but" repeat this feeling.

-"You saw! Damn, she was about to enter the basket.” (Act locutionary)

-Illocutionary act: inquiry \& assertion

-Perlocutionary act: questioning indignation

Index of anger, the use of swears words described the mood of the student, unhappy with having missed the goal. Thus the form of a question would be synonymous with indignation. This act is also complemented by an assertion that it is a question mark. This commits the recipient to provide an explanation of why they failed.

-"You missed your cart because you shot before attaching the panel.” (Act locutionary)

-Illocutionary act: assertion

-Perlocutionary act: reproach \& injunction

The use of the argumentative justification connector of this statement gives an informative purpose in appearance: the pupil explains to his colleague his fault, hence the reproach. The perlocutionary act is conveyed by the adverbial of time "before they shoot". Thus the reproach is completed by an injunction, the speaker orders his teammate to concentrate more.

"Normally you pass me the ball, I am better placed than you and you know I do not usually miss." (Act locutionary)

-Illocutionary act: assertion

-Perlocutionary act: pride and reproach

This is an argumentative assertive sentence through which the speaker addresses a criticism to his friend who lost a chance to shoot. It is also informative in that it demonstrates a proof connector; this statement is not only a vehicle but also a reproach to the other to inform him of his expertise in the game. He's presented in fact as an expert in "shots 6 meters", hence his pride index vanity.

"Oh but what game and what a horrible team!!” (Act locutionary)

-Illocutionary act: inquiry

-Perlocutionary act: reproach and sarcasm

Exclamatory nature, this statement is in a rhetorical question, which goal is to bring the group to reflect on the quality of play. This propositional content aims to show that the speaker expresses his dissatisfaction with the performance of his team, that statement is sarcastic or mocking. He derides the inert attitude of his comrades. This sarcasm is just another form of reproach.

"You know, it looks like they are playing with 4 boys and we were playing with four girls and a boy" (Act locutionary)

-Illocutionary act: assertion

-Perlocutionary act: offend

In this statement, the speaker makes a game analysis, comparing his team to that of the opponent. In this sense, the phrase at the base assertive, informs us about the members of each group: a finding based on sex. However, a careful study of the game reveals an antiphrasis which aim is sarcastic: Although they play with girls the opposing team arrives to lead the game, this is not the case for boys. 


\section{- Meeting 2}

"Please you try to move more" (act locutionary)

-Illocutionary act: assertion

-Perlocutionary act: order

Consequence of a relaxation in the game, the speaker addresses order to his teammates mitigated by a form of polite "please".

"If you were well organized on the ground, surely you would not have lost" (Act locutionary)

- Illocutionary act: assertion

- Perlocutionary act: criticism

The statement reformulates some explanations about the misplacement of some elements of the group, which shares have proved disastrous as they conceded goals. Far from being an informative purpose, this statement sends a caller: criticized teammates involved better position themselves in the field. It follows that the assertion vehicle committing a reproach to all gets better organized.

"You do not play with us or what?" (Act locutionary)

-Illocutionary act: inquiry

-Perlocutionary act: order

This oratory question is addressed to an individual of the same group for questioning to which team he really belongs. Therefore, the question implicitly informs us on the laxity and inertia of the individual in question. It calls to order, requiring him to change his attitude.

\section{- Meeting 4}

“God, our opponents are so all over the field I feel they outnumber us!!”

-llocutionary act: assertion

-Perlocutionary act: criticism

Through the exclamation, the speaker expresses a shame due to the superiority of the opposing team. As a result, this statement explicitly praises the superiority of the opposing team. It informs us that superiority among other games quality of his team, is even an unsatisfactory source of shame in his eyes as to the complaint made to his colleagues.

"You reproach me because I dribbled once!” (Act locutionary)

-Illocutionary act: assertion

-Perlocutionary act: criticism

Unlike other statements, the propositional content contains a performative act, since we explicitly inform the perlocutionary.

"But it is not the army not to commit errors." Do not do this! Do not do that! Do not move! ... "Is what we are playing basketball or something?” (Act locutionary)

-Illocutionary act: assertion/order/inquiry.

-Perlocutionary act: inform/reproach.

This action meets three speech acts: the statement begins with an utterance reminding others of the school and military context. The injunctive sentences prove explanatory since they explicate how the criticisms are in advance of a military nature. As a result, this injunction is no obligation. Their target is deformed toward goals purely argumentative. The statement ended with a question of value-reproach. The speaker criticized his teammate who reminds him firmly your army?

- Meeting 6

"So in any case you let the other score, you have to defend well darling, you're a good defender" (act locutionary)

- Illocutionary act: assertion

- Perlocutionary act: criticism \& order

The speaker is engaged in the judgment; the keeper considers that he has failed in his duties. He reminds him of his duties, which are keeping the cage, while reminding him that he must keep his post. As a result, this statement contains an informative complaint leading to an injunction, that of keeping the position where he is assigned.

\section{- Meeting 7}

"Yes we miss opportunities because net is not serious or intelligent Yes we miss opportunities because net is not serious or intelligent." (Act locutionary): this same statement twice in a row. 
-Illocutionary act: assertion

-Perlocutionary act: criticism if this act is primarily type assertive as it seeks to analyse the causes of failure, where the recurrence of justification connectors "because on the other hand," the statement is not oriented information, even if all recipients share the same group, but essentially aims to address a complaint to improve the quality of play.

"But wait Chomakher, you play anyway with four other players is not it??” (Act locutionary)

-Illocutionary act: inquiry

-Perlocutionary act: offense

The query referred to the pupil in no way intended to create pure information, but a reproach. It is a matter of reproach or offense caused in a bad attitude: the student in question has proved selfish, ignorant member of his team. Thus, the intervention acquires the role of offense so that to call to order.

- Meeting 8

"No it's rather your mother... but of course you! You know, if we lose today, it is because of you..."

- Act locutionary: assertion

- Illocutionary act: offense/caution

The speech opens with an offense. Through irony, the speaker shows himself mocking and empowering the mother of the pupil at fault. Moreover, he does not hesitate to rectify this by empowering the student. This mockery has no other purpose than to prepare and justify the warning enclosed in the statement. The assertion is structured around the assumption followed by a direct consequence of the student who will be solely a responsible wrongdoer.

"In the name of god, tell me what you think at that moment?"

-Illocutionary act: inquiry

-Perlocutionary act: criticism

Adopting an interrogative form in appearance, this statement does not elicit any information request. It is a reproach to a group that seems to wander and not to be interested in the on-going discussion. This call to order is to involve more elements lost in the discussion.

"Congratulations Capello and what else"? (Act locutionary)

-Illocutionary act: inquiry

-Perlocutionary act: offense

The statement opens a compliment form, since it is not intended to gratify the person in question. Index of tension between the receiver and transmitter, the compliment mocks the pupil so that it looks like a mockery, which is reinforced by the query except sessions five and six that remain devoid of understanding and where the three acts will join the rest certifying many beautiful structures implied. The statements are assertive, interrogative, exclamatory or injunctive, produced under the remuneration mainly in the sphere of criticism. This result is not surprising to us as long as it is a collective game that is raising the competitiveness of individual and collective. Moreover, these acts insinuate some tension within the same group which causes are many: poor behaviour of some dissatisfaction with the tactics of the game or score. Others mentioned, lower values also convey some tension within the group, since they generate a response: this is the case of the offense, the assertion or request information.

Also mention that the complexity of verbalization is associated with the emotional side of pupils. Decision-making, especially with "at least one alternative with justification," has a dramatic impact on the functioning of certain pupils. The confrontational aspect is that the discussion resulted in the answers in the form of "criticism": it feeds data exchange between pupils and opens new perspectives to the discussion. Note here that the "blame" is not necessarily designed as direct accusations likely to cut short the discussion envying a powerful struggle, but as catalysts to raise other issues and provide other dimensions verbalization. These criticisms come sometimes in the form of direct speech acts and other times in the form of indirect speech acts "elliptical expression for" indirect speech acts made under the guise of another speech act "(Kerbrat-Orecchioni, 2008: p. 52). Example of direct criticism:

Saloua: -I did not mean to make trouble with the teacher but it is because of your selfishness that we did not score .

Youssef: -what are you talking?

Saloua: -I mean you, the two boys!

Youssef: -tell me! Do I refused once you pass the ball? 
Saloua: -no, but for 2 times you shoot although you are not well placed when I was alone. You could have let me pass.

Example of indirect reproach:

Zied: -We would have won with a score range and play a lot better, but with these two girls I do not think it's possible.

Salma: -yes, certainly, it is girls who are in the process of lost opportunities!

The first charge "-I mean you, the two boys" is considered an act of direct language to the extent that the speaker speaks directly to recipients. The sentence takes the form of a declarative (Kerbrat-Orecchioni, 2008), may correspond to this case as accountability or even a charge. The second formulation "-yes, certainly, it is girls who missed the opportunity!” Is an indirect reproach because it is expressed through a query. Indeed, this set will always be interpreted as meaning indirectly “-yes, certainly, it is the boy who missed opportunities" with this declarative form. Through this act of indirect language, girls can easily empower boys but that they can meet and counter-argument is not directly affected by the criticism. These indirect discourse expressions represent the extreme degree of conversation. "We talk in such cases of indirect speech acts (...), Searle has shown that the indirect formulations in many cases could be correlated with certain conditions for success of the speech act that is to be conduct” (Kerbrat-Orecchioni, 2008: p. 52). The girls have chosen this example to implicate the speech to affirm the total liability of boy's vis-à-vis losses shot (Searle, 1982). If the debate becomes denser and more dynamic, the criticisms in context may represent an indicator of the growing involvement of players in trade. The responses evolution in the form of reproach throughout the cycle marks an evolution of a new parameter of decision-making. Pupils, by questioning what their peers come to verbalize, actually begin to make more complex decisions that invalidate those already taken or attitudes initially admitted. The multiplicity of possible interpretations about the game and is operationalized in the debates and discussion of views.

Therefore, the evolution of this response category gives rise to other strategies that allow a word collective decision-making

\subsection{Power Relations between Boys and Girls}

\section{Meeting 1 (A \# C)}

- Salim: "We must preserve the guys" Illocutionary act: assertion Perlocutionary act: order, injunction

-Saloua: "The solution is to be more efficient in attack by attacking with more players"

Illocutionary act: assertion

Perlocutionary act: statement through this brief exchange, it should be noted that the boy who dominates the discussion, since he produces an injunctive speech involving the whole group. Nabila, although did not agree with him, since she directs the exchange to another solution that takes the assertive form. As a result, her speech is no longer a proposal. It does not require anyone. Other things would have been great if she had used the same form of speech than her colleague. At that time, her statement would cancel the first to get the better of him.

\section{Meeting No. 2}

- Rami: We will try to make a good first gap.

Illocutionary act: assertion

perlocutionary act: order

-Anis: But you're not an advocate with us or what?

Illocutionary act: inquiry perlocutionary act: criticism

Try to ensure the rebound.

Illocutionary act: injunction

perlocutionary act: order.

This is not normal not to move anywhere on the field.

Illocutionary act: assertion

perlocutionary act: criticism

At first glance, it seems that the balance of power falls to Ramzi, since he imposes onto his colleagues a game plan involving the whole group, thus he appears as the strategist for the group. These findings would be retained if not for the intervention of his friend who just challenged everything. His statements, both interrogative as well as assertive, prove the reproaches that challenge what is already said. This injunctive form conveys a reproach, and is not meant to remain inter $t$ but will complement the criticisms. From this brief exchange, we deduce a tension between the members of the same team. Regarding the balance of power, it remains to preserve the boy? 


\section{Meeting No. 3}

-Salim: "We need to expand more away."

Illocutionary act: injunction

perlocutionary act: order

"To cover back."

Illocutionary act: injunction

perlocutionary act: order

"We must make a good gap so we can play quietly." Illocutionary act: injunction perlocutionary act: order

-Anis: "We need everyone involved to have the ball". Illocutionary act: injunction

perlocutionary act: order "As long as you do not try to pull the ball, you can never win." Illocutionary act: assertion perlocutionary act: statement "We must cooperate in order to snatch the ball." Illocutionary act: injunction perlocutionary act: order "We must persevere". Illocutionary act: injunction perlocutionary act: order for both Salim and Anis, they argue phrases conveying injunctive orders as to how the game in this sense exchange offers projects to be undertaken to complete the score, hence the use of injunctive forms: as many instructions to be followed by all team members.

\section{Meeting No. 4}

-Monji: "We will try not to throw the ball no matter how "Illocutionary act: injunction perlocutionary act: order "Try to avoid long passes "Illocutionary act: injunction perlocutionary act: order "We will try to opt for short passes” Illocutionary act: injunction perlocutionary act: order

-Sarra: "We will try to be faster in attack" Illocutionary act: injunction perlocutionary act: order

-Helmi: "We will try to leave their less space by being closer" Illocutionary act: injunction perlocutionary act: order "We need to reduce the gaps by a man-to-man marking" Illocutionary act: injunction perlocutionary act: order

-Youssef: “Try not to let them play freely” Illocutionary act: injunction perlocutionary act: order

-Helmi: "It must mark the benefit because they always find spaces to score" Illocutionary act: assertion perlocutionary act: order

-Sami: "You have to mark them more because they are still spaces, we can score at any moment.” Illocutionary act: injunction perlocutionary act: order

Four people involved in the exchange, one girl and three boys. Although the speech of Monji is injunctive offering prospects of play, further Helmi remains perfectible. It is not only because of injunction proposals that engage everyone; they are a complement by argumentative connectors. In this sense, it resorts to the justification and the consequence for convincing. This applies also to Sami that in addition to joining in, he uses the justification. The fact remains that the speech is more consistent for boys than for girls/Sarra simply reformulates an order without explanation. It remains less perfectible, dominated by boys.

Meeting No. 5

-Salim: "We need to focus” Illocutionary act: injunction perlocutionary act: order

-Hedi: "We must take every opportunity” Illocutionary act: injunction perlocutionary act: order "He no bullet will be missed". Illocutionary act: injunction perlocutionary act: order

-Salim: "Let's put the ball on the ground and play as usual.” Illocutionary act: injunction perlocutionary act: order

-Saloua: "It is necessary to notice and take away as long as there’s space can be labeled " Illocutionary act: injunction perlocutionary act: order "You could have let me pass because I am more than you" Illocutionary act: assertion perlocutionary act: statement

Actors in the game continue to produce oriented game tactics and utterances to be able to get back in the game and lead the score. Paradoxically, Saloua's speech remains the richest since its injunctions are supplemented by explanatory argumentative structures. She uses the argument to demonstrate the merits of her proposals. Unlike her, the injunctions of the boys remain short and dry, without any explanation. From a strictly qualitative perspective, the balance of power tends to be reversed in favour of girls.

\section{Meeting No. 6}

-Monji: "I am also the last defender and I am responsible for any defence. So I have to leave, I must anticipate.” Illocutionary act: assertion/injunction perlocutionary act: declaration/order

-Ahmed: “We must reorganize Mr” Illocutionary act: injunction perlocutionary act: order

-Hedi: "We must learn from far and all distances" Illocutionary act: assertion perlocutionary act: order 
-Ramzi: “This is why we must take advantage of these stray bullets” Illocutionary act: assertion perlocutionary act: statement

-Salah: "Mr, we must continue to play together primarily because this is our strength" Illocutionary act: assertion perlocutionary act: statement

-Dalila: "We must organize now to stop the power and dominion” Illocutionary act: assertion perlocutionary act: order "Believe me they can easily dominate" Illocutionary act: assertion perlocutionary act: statement

Overall, all utterances are referred to project orders as to how the game is played, which involves everyone. The speech injunctive boys are supplemented by the argument. Whether supporting or consequential damages, boys' arguments give us the reasons and the expected consequences to those decisions. Dalila is part of the same view twice. The quantitative dimension of discourse produced by the opposite sex unfortunately distorts the presence of the female. In this sense, the boys again dominated trade.

\section{Meeting No. 7}

-Salim, "You can score without firing. Inevitably, like that, you can place the ball” Illocutionary act: assertion perlocutionary act: criticism

-Dalila: “Mr, it is poorly organized," Illocutionary act: assertion perlocutionary act: criticism "We must stand here better than on any field.” Illocutionary act: injunction perlocutionary act: order

-Salah: "We need to tackle more than that" Illocutionary act: injunction perlocutionary act: order

-Anis: "We must reverse the situation” Illocutionary act: assertion perlocutionary act: order "Attack instead of defending” Illocutionary act: injunction perlocutionary act: order

-Helmi: "We must move the ball, then attack" Illocutionary act: assertion perlocutionary act: order

-Dalila: "We must go as quickly as possible towards their cage” Illocutionary act: assertion perlocutionary act: order

Two key moments characterize the verbal exchange: criticism and perspectives proposed to address them. As a result, from a strictly syntactic, there are two types of sentences: the assertive and injunctive relieves. Except the Dalila speech, all statements, whether assertive or conveying orders remain laconic offering only solutions for Dalila back in the game for its part is not content merely to rephrase a criticism; she complements it by injunctive relief as a structure solution. This made the speech sounds remain the most structured.

\section{Meeting No. 8}

-Hedi: “We must continue to play like that” Illocutionary act: assertion perlocutionary act: order

-Ali: "We must ask if the ball is not going to overcome this problem” Illocutionary act: assertion perlocutionary act: order

-Hedi: "We must stand if we are not going to win" Illocutionary act: assertion perlocutionary act: order

-Monji: "Do not conceding goals" "You have to call in the free spaces” illocutionary acts: assertion perlocutionary acts: order

-Hedi: "We must seize the opportunities” Illocutionary act: assertion perlocutionary act: order

-Sami: "we avoid the bullets missed stupidly” Illocutionary act: assertion perlocutionary act: order

-Saloua: “Mr, pull” Illocutionary act: assertion perlocutionary act: order

-Sami: "Do not shoot, you have to go fix the guard for dribble, the cage is so small to draw far" Illocutionary act: assertion perlocutionary act: order "We must approach the maximum possible guardian before taking any decision.” Illocutionary act: assertion perlocutionary act: order "We will attack in pairs and each time we change the role” Illocutionary act: assertion perlocutionary act: order.

Whether produced by girls or boys, all type of assertive statements are referred to with the order, they are all instructions to remedy the failure. Most are indeed accompanied by a brief argument that explains the cause or the consequence of the performed act. Nabila certainly produced a well-structured speech except that boys, who provide quantitatively more of this type of discourse, dominate it. Of all interventions is that of Sami which remains the most consistent. Although girls seem to take part in the discussion, their actions remain less important. The analytic statements they produce remain perfectible little or negligible compared to those of the opposite sex. The latter are never able to take over the boys.

\section{Interpretation}

The new language of sciences in applying the theory of speech acts (Austin, 1970) claims that language is primarily not at a mirror of thought, but a means to influence others by including it in context in a project influence?. If the speech has a cooperative characteristic (of anticipating the effects on others to produce while in- 
corporating each other's own discursive strategies thereof) (Grice, 1979), it is also based on a principle of relevance (which assumes that every speaker expresses himself with his own sense of perspective and against its own frame of reference) (Sperber \& Wilson, 1989). Thus, the pragmatic dimension mainly located at any speech act is to return as soon as we proceed with a discourse analysis.

In this study based on linguistic interactions in learning situations, the pragmatic discourse is very helpful for the treatment of the corpus collected during exchanges between students. If language is a form of action, if any statement is already loaded pragmatically, that burden lies in its propensity to act on others and to produce effects. Discourse analysis is then released from the content analysis in that it is no longer to discover the hidden meaning in a text, but accede to employment that it is being compared to directly or indirectly desired effects.

To describe the meaning of a word or text is to describe the actions that refer to it and/or allow it to accomplish, it denotes the intentions and approaches of speakers engaged in the interaction. The language game is the game of relationships between partners, relationship to knowledge and action. It ultimately raises the definition of the speaker as actor co-constructing interactions. The essentially illocutionary act of language based on the fact that statements can be described as acts (e.g., ask affirmations, issue orders, dispute a fact, ask questions, make promises and/or criticisms ... etc.), pensionable or non-peer context, they say simply because they do say.

On this basis, we can say that what is shared in trade is the source of what is understood and learned. The individual interpretation of part of the game reflects the ability of a player's strategies and their developments. Thus, the speech offers a free interpretation of the game, this can be either open or adversarial or confrontational. In fact, speech acts occupy a node in the didactic situation.

Interactional strategies are strongly influenced by the discourse markers that influence the type of speech act mobilized by the speaker. More importantly, the circulation of knowledge in and through the action involves exchanges between partners in the game. Our analysis will take into account the presence of these discourse markers that guide the interpretation of the hearer. A discourse marker of explanation and reformulation can be for example "that is to say," or can be used in judgment (e.g., "therefore") or reformulation. A marker used to establish mutual understanding between the partners language exchange. It may also consist of nonverbal means (e.g., smile, nod ... etc.).

To understand the phenomena of verbalization, conversational settings must be taken into account. A pragmatic study is still based on the parameters of the utterance. Any conversation is engaged, that is to say, contextualized; it is enrolled in a pragmatic and obeys to the parameters of the utterance that is, the space-time framework and the speech actors (shifters). Therefore, verbal interactions can be studied on the basis of its logical connectors that can lead the caller to the conclusion desired by the issued message. Better yet, the linguistic markers (pronouns, adverbs) may help understand the organization and structuring of the interactive discourse.

In conversational and argumentative approaches (Roulet, 1981; Moeschler, 1985), the study does not only reflect the structure of the language but also its position which is based on the desired effects. The conversational analysis therefore aims to identify the content and purpose of the conversation in terms of effects, while permit you to understand the mechanisms through which the speakers communicate (Moeschler \& Reboul, 1994). In this approach, you must enter the order of the trade while taking into account reports of fits with the obtained effects: verbal material (language unit), nonverbal material (posture, gestures, laughter ... etc.). It is therefore to study the organization of local and global conversations where the speaker plays a key role as a "manager" and a responsible for the conversation.

Commonly known as the "conversational pragmatics", this current study has the objective to dissect the mechanisms of interlocution. In other words, its area of research will be its actual use in context and the aims sought. First, we can say that there is no "isomorphism" between language and the formal rules of grammar. The lexicon is semantically over determined, which over determination is done by the participants and context. Our study will therefore focus on conversational pragmatics, which will be most appropriate to the study of the corpus. Recall here that the group games, especially basketball, are games where situations are reversible or uncertain. This is where the verbalization comes as a condition of mutual understanding, even if there are misunderstandings and incomprehension. This justifies the legitimacy of this study.

\section{Conclusions}

The language in action is reducible to thinking (and vice versa) or to the implementation of motor actions. By a shift that leads the intention of the language, the subject is freed from the grip of immediate and emotional things; to put distance makes them appear, to present them as a constructed reality to be shared. In doing so, the 
formalization of language allows the motor action, naming, and a scheduling heuristic that motor experience alone will not significantly?

The speech motor action gives therefore, a potential exploration and sharing power with others. It is from this perspective that comes into the meaning of things for itself. If the language is in fine work of liberation, it is also the return of a universe, the body world in action (Wallian et al., 2004).

Reflection on the act in human movement involves both behaviours (as objectively observable) which motor behaviour as intentional processes and the underlying decision strategies situated in the context. This reflection involves a multidisciplinary approach, ranging from the philosophy of action (phenomenology and hermeneutics, argumentative rhetoric) and knowledge (constructivist epistemology), semiotics (discursive pragmatics, discourse analysis), the educational disciplines, and the intervention of science (social psychology, Cognisciences, cognitive ergonomics).

\section{References}

Austin, J. L. (1970). Quand dire, c'est faire. Paris: Seuil.

Grice, H. P. (1979). Logique et conversation. Communications, 30, 57-72. http://dx.doi.org/10.3406/comm.1979.1446

Kerbrat-Orecchioni, C. (2008). Les actes de langage dans le discours. Tome1: Approche interactionnelle et structure des conversations (Nouvelle édition). Paris : Armand Colin.

Moeschler, J. (1985). Argumentation et conversation. Eléments pour une analyse pragmatique du discours. Berne: Peter lang.

Moeschler, J., \& Reboul, A. (1994). Dictionnaire encyclopédique de pragmatique. Paris : Seuil.

Roulet, E. (1981). Echanges, interventions et actes de langage dans la structure de la conversation. Etudes de linguistique appliquée, 44, 7-39.

Searle, J. R. (1982). Sens et expression. Trad. Fr. Paris: Minuit.

Sperber, D., \& Wilson, D. (1989). La pertinence. Paris : Minuit.

Wallian, N., Chang, C. W., Nachon, M., Couty, B., \& Gréhaigne, J. F. (2004). Student Action Reading and Meaning Attribution: Towards a Model of Interpretation Register in Game Play. In R. Light, \& K. Swabey, \& Brooker, R. (Eds.). Proceedings of the 2nd Internationale Conference: Teaching Sport and Physical Education for Understanding. Melbourne (AU): University Press.

Zghibi, M., Zerai, Z., \& Rezig, M. (2009). Verbalization’s Direct Effects on Action’s Strategies and Decision Makings among Pupils at a Football Cycle. Journal of Research about the Intervention on Physical and Sportive Education, 16, 118-140. 